\title{
Descriptive Study of 32 Cases of Doxycycline-Overdosed Calves
}

\author{
M. Brihoum, H. Amory, D. Desmecht, D. Cassart, S. Deleuze, and F. Rollin
}

\begin{abstract}
Background: Reports of doxycycline-induced toxicity are limited despite common use of this antibiotic to treat infectious respiratory disorders in calves.

Objective: To describe previously unreported kidney lesions and diagnostic test results in doxycycline-overdosed calves and to compare these results with other findings reported previously.

Animals: Thirty-two calves that presented with adverse effects after receiving high doses of doxycycline as a treatment for mild respiratory disorders.

Method: Retrospective review of medical records.

Results: Clinical examination identified mainly lethargy, dyspnea, cough, tongue paresia or paralysis associated with dysphagia and sialorrhea, tachycardia, tachypnea, and signs of myopathy. Blood analysis indicated increases in creatine kinase, lactate dehydrogenase, aspartate aminotransferase, and sorbitol dehydrogenase activities and increased serum creatinine and urea concentrations. ECG recordings and Doppler echocardiography examination identified ventricular premature beats and a decrease in left ventricular global and systolic function, respectively. Necropsy and histopathology disclosed necrosis of the myocardium, tongue, and some striated muscles, acute renal tubular necrosis, and fatty degeneration or congestion of the liver.

Conclusions: Most of these findings corroborate previous observations made in doxycycline-overdosed calves, and further suggest myocardial and striated muscular toxicity as well as renal toxicity in doxycycline-overdosed calves.
\end{abstract}

Key words: Cattle; Kidney; Liver; Toxicity.

$\mathbf{S}$ ince 1993, several reports described sudden death occurring in calves after oral intake of high doses of doxycycline, a semisynthetic broad-spectrum tetracycline, in the Netherlands, ${ }^{1}$ Canada, ${ }^{2}$ Israel, ${ }^{3}$ and Belgium. ${ }^{4}$ All of the reported calves received doxycycline to treat mild respiratory disorders or prophylactically to prevent respiratory problems in calves living with sick ones. In the reported cases, clinical signs, including dullness, lack of appetite, sialorrhea, dysphagia, arrhythmias, and pulmonary distress, were observed 1-5 days after the calves received 3-10 times the recommended dosage of doxycycline (recommended dosage, $5 \mathrm{mg} / \mathrm{kg} \mathrm{q} 12 \mathrm{~h}$ ). Sudden death occurred 1-5 days after beginning treatment. The main reported postmortem findings were pulmonary edema and myocardial degeneration and necrosis. Myopathy of the tongue and of some striated muscles also has been reported. ${ }^{4}$

In this study, clinical data, results of diagnostic tests, postmortem findings, or some combination of these were obtained from 32 calves with a history of complications after oral doxycycline overdosing in order to compare

From the Department of Companion Animals and Equids, Equine Clinic, B41 (Brihoum, Amory, Deleuze), Department of Morphology and Pathology, Systemic Pathology, B43 (Desmecht, Cassart), and the Clinical Department of Production Animals, Clinic for Ruminants, B42 (Rollin), Faculty of Veterinary Medicine, University of Liège, Liège, Belgium. This study was performed at the Faculty of Veterinary Medicine of the University of Liege, Belgium. Part of the content of this paper has been presented in posters session at the $23 \mathrm{rd}$ World Buiatrics Congress, July 11-16, 2004, Québec, Canada.

Corresponding author: M. Brihoum, Department of Companion Animals and Equids, Faculty of Veterinary Medicine, University of Liège, Equine Clinic, 20, Boulevard de Colonster, B41, Sart Tilman, 4000, Liege, Belgium; e-mail:mounir.brihoum@ulg.ac.be.

Submitted September 2, 2009; Revised April 24, 2010; Accepted May 21, 2010.

Copyright (C) 2010 by the American College of Veterinary Internal Medicine

$10.1111 / j .1939-1676.2010 .0560 . x$

\begin{tabular}{ll}
\multicolumn{2}{l}{ Abbreviations: } \\
AST & aspartate aminotransferase \\
ATN & acute tubular necrosis \\
BB & Belgian Blue \\
BUN & blood urea nitrogen \\
BW & body weight \\
CI & cardiac index \\
CK & creatine kinase \\
CO & cardiac output \\
ET & left ventricular ejection time \\
FS & fractional shortening \\
FVI & flow velocity integral \\
LDH & lactate dehydrogenase \\
LVIDs and d & left ventricular internal diameter in systole and diastole \\
PEP & pre-ejection period \\
PFV & peak flow velocity \\
SDH & sorbitol dehydrogenase \\
SI & stroke index \\
SV & stroke volume \\
TTP & time to peak \\
\hline
\end{tabular}

them with previously reported findings and to describe previously unreported effects on the liver and kidney.

\section{Material and Methods}

This study was performed by reviewing medical records of 32 calves referred either alive or dead to the veterinary medicine faculty of the University of Liège with a clinical history of either new nonrespiratory clinical signs or sudden death after administration of high doses of doxycycline.

Each calf that was referred alive underwent a conventional clinical examination on admission at the clinic. Blood was collected from these calves. Creatine kinase (CK), lactate dehydrogenase (LDH), aspartate aminotransferase (AST), and sorbitol dehydrogenase $(\mathrm{SDH})$ activities and total serum protein concentration were evaluated, and serum protein electrophoresis was performed. 
Vitamin E, selenium, serum creatinine, and blood urea nitrogen (BUN) concentrations were determined.

\section{ECG Examination}

ECG tracings were recorded in three of the affected calves with a bipolar base-apex lead and a 1-channel electrocardiograph. ${ }^{\mathrm{a}}$

\section{Echocardiographic Examination}

A Doppler echocardigraphic examination was performed in 2 calves ( 2 of the 3 calves that underwent ECG examination) with a $2.5 \mathrm{MHz}$ phased-array sector scanner ${ }^{\mathrm{b}}$ and recorded on VHS tapes for further analysis. The calves were examined standing. An ECG was recorded simultaneously with the echocardiographic images.

Thickness of the interventricular septum and the left ventricular internal diameter (LVID) were measured on a right parasternal M-mode short axis view of the left ventricle at the level of the papillary muscles and chordae tendinae.

The aortic diameter (Ao) was measured on a right parasternal 2D long-axis view of the left ventricular outflow tract at end-diastole, at the level of the aortic valve annulus (defined as the insertion point of the aortic valve leaflets).

Left ventricular fractional shortening (FS) was calculated by the conventional formula. ${ }^{5}$

Aortic flow velocity integral (FVI), peak flow velocity (PFV), left ventricular ejection time (ET), preejection period (PEP), time to peak flow (TTP), and heart rate (HR) were measured from the pulsed-wave Doppler tracing of the aortic flow obtained from a left parasternal 2D long-axis view of the left ventricular outflow tract.

Stroke volume (SV) and cardiac output (CO) derived from the Doppler measurements were calculated by the conventional formula. ${ }^{5}$

Stroke index (SI) and cardiac index (CI) were calculated, respectively, by dividing the SV and the $\mathrm{CO}$ by the calf's body weight (BW). The ratio PEP/ET also was calculated.

\section{Necropsy and Histopathology}

Calves that died during hospitalization or that were referred dead underwent necropsy. Gross postmortem lesions and blood chemistry results justified sampling fragments of myocardium, tongue, lung, kidney, and some striated muscles for histopathological examination. All tissue samples were fixed in $10 \%$ buffered formalin, trimmed and embedded in paraffin wax according to standard laboratory procedures. Tissue sections of $4 \mu \mathrm{m}$ thickness were stained with hematoxylin and eosin (H\&E) and examined under light microscopy.

\section{Results \\ Clinical History}

Eighteen calves (11 Belgian Blue [BB], 4 Holstein Friesian, and 3 Red Holstein; 13 females and 5 males; 4 to 14 weeks old; from 5 farms) were referred alive and 14 others (14 BB; 9 females and 5 males; 6 to 16 weeks old; from 8 farms) were referred dead. All of these calves received doxycycline to treat moderate respiratory disorders. However, doxycycline treatment was spontaneously reported in the history of only a few referred cases. In the other cases, it was reported only several days after admission. Consequently, calves of this group did not undergo the same diagnostic testing as the others. Apart from respiratory disorders, no other clinical signs were observed in these calves before doxycycline treatment.
For calves that were referred alive, different proprietary brands of doxycycline hyclate were used on the 5 farms. Doxycycline was mixed in cow's milk or milk replacer and given to calves twice daily. Calculations indicated that, on 4 farms, the administered dose of doxycycline was 3 to 7 times higher than the recommended dosage of $5 \mathrm{mg} / \mathrm{kg} \mathrm{q} 12 \mathrm{~h}$. On $1 \mathrm{farm}$, doxycycline was used at the recommended dosage but was not well mixed with milk replacer so that lumps formed and, consequently, some calves ingested more doxycycline than others. On their farms of origin, referred calves were fed either milk or milk replacer only or milk and solid food.

Calves were hospitalized because of lack of response to doxycycline treatment or because of appearance of new nonrespiratory clinical signs. Problems appeared only in doxycycline-treated calves. On one of the farms included in the study, the referring veterinarian mentioned that some calves belonging to the same group as those referred to our clinic did not receive doxycycline but a combination of lincomycin and spectinomycin to treat their respiratory problems. None of these latter calves showed clinical signs comparable to those observed in the doxycycline-treated calves.

\section{Clinical Examination}

In the 18 calves referred alive, clinical signs appeared 2 to 4 days after oral doxycycline was started. Tongue dysfunction and sialorrhea were reported to be the earliest clinical signs in the affected calves. The most frequently observed signs were lethargy (18/18), variable degrees of dyspnea (18/18), variable degrees of inappetence (16/18), cough (11/18), tongue paresis or paralysis associated with variable degrees of dysphagia $(9 / 18)$, tachycardia (heart rate $>110$ beats/min; $8 / 18)$, weak pulses $(8 / 18)$, sialorrhea $(8 / 18)$, and tachypnea (respiratory rate $>50$ breaths $/ \mathrm{min} ; 7 / 18$ ). Nine calves showed clinical signs suggestive of myopathy shortly after doxycycline administration. Other clinical signs such as cardiac arrhythmias (6/18), mydriasis (6/18), or diarrhea $(2 / 18)$ also were observed in some calves.

Sudden death occurred in 5 calves during or soon after clinical examination and 3 others died 4 to 12 hours after admission. The 8 dead calves were submitted for postmortem examination. The 10 other calves recovered and survived.

\section{Blood Analysis}

Blood was obtained in 13 of the 18 calves (Table 1). The 5 other calves died before sampling.

When performed, blood analysis indicated increases in CK (13/13), LDH (8/8), AST (5/6), and SDH (6/6) activities, increases in serum creatinine and BUN (4/7) concentrations and low concentrations of selenium (2/2) and vitamin $\mathrm{E}$ $(1 / 2)$. In 6 of the sampled calves, CK activity was $>10,000$ IU/L. Blood analysis also disclosed hypoproteinemia (3/6) and, in calves for which serum protein electrophoresis was performed, hypogammaglobulinemia (5/5).

\section{ECG}

ECG examinations were performed in 3 calves 7 days after doxycycline treatment had been discontinued and 


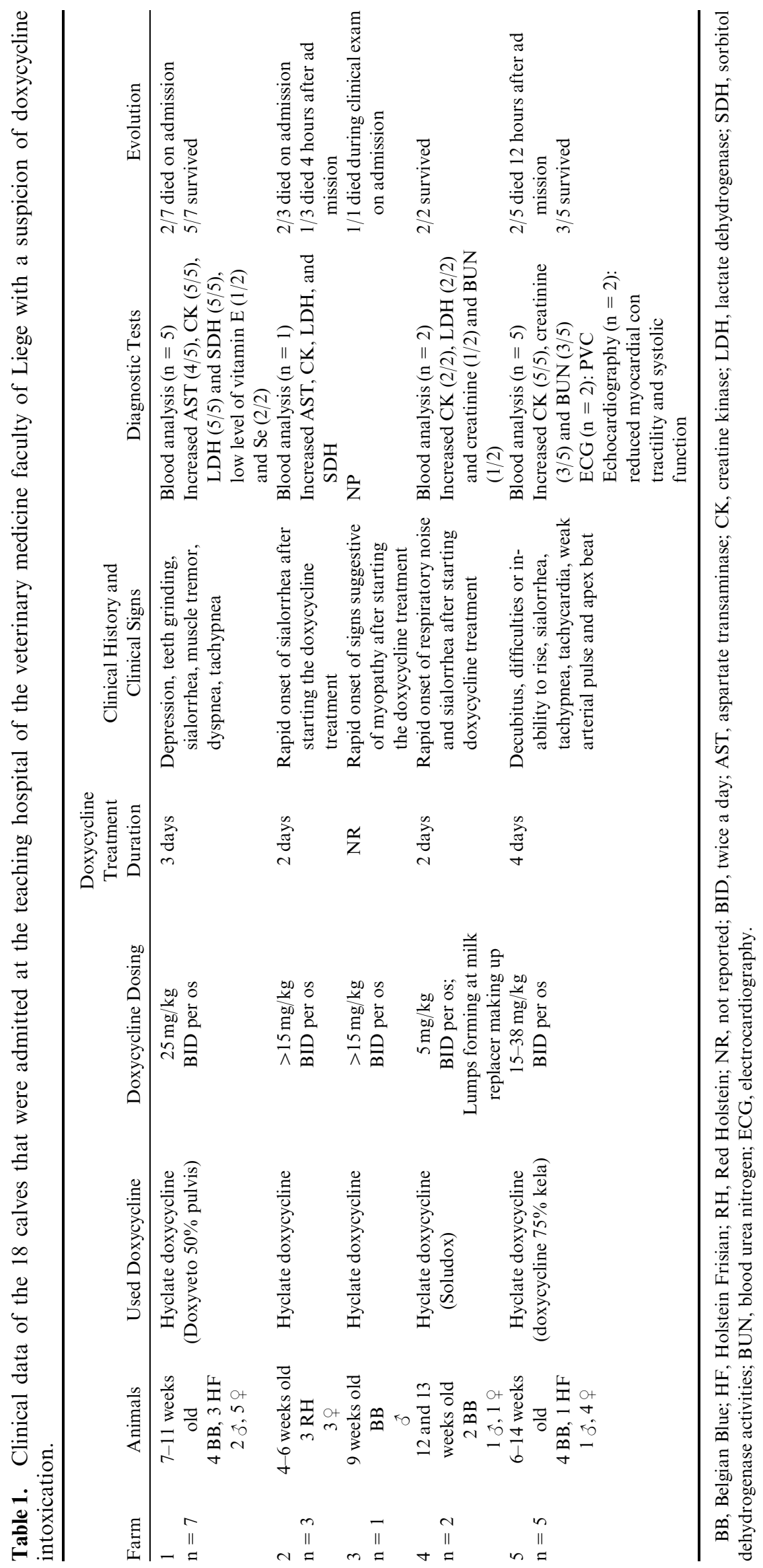


Table 2. Blood analysis results in calves with a presumptive doxycycline toxicity.

\begin{tabular}{|c|c|c|c|c|}
\hline & $\mathrm{n}$ & Range & Median & $\begin{array}{c}\text { Reference } \\
\text { Range }\end{array}$ \\
\hline $\mathrm{CK}(\mathrm{IU} / \mathrm{L})$ & 13 & $635-445,800$ & 4,950 & $128-244$ \\
\hline LDH (IU/L) & 8 & $3,430-40,375$ & 9,428 & $1,691-2,618$ \\
\hline AST (IU/L) & 6 & $125-8,900$ & 1,745 & $70-130$ \\
\hline SDH (IU/L) & 6 & $55-200$ & 78 & $10-50$ \\
\hline Creatinine $(\mu \mathrm{mol} / \mathrm{L})$ & 7 & $105-1,038$ & 261 & $88-176$ \\
\hline BUN (mmol/L) & 7 & $2.80-37.7$ & 11.36 & $1.66-10.73$ \\
\hline Vit. E (mg/L) & 2 & $1.30-9.9$ & 5.6 & 4-9 \\
\hline $\operatorname{Se}(\mu \mathrm{g} / \mathrm{L})$ & 2 & $39-40$ & 39.5 & $>70$ \\
\hline $\mathrm{TP}(\mathrm{g} / \mathrm{L})$ & 6 & $51-65$ & 61 & $61-73$ \\
\hline Alb (g/L) & 5 & $26-32$ & 29 & $23-31$ \\
\hline$\alpha-\operatorname{glob}(g / L)$ & 5 & $9.9-13.6$ & 12.9 & $9.4-12.6$ \\
\hline$\beta$-glob $(g / L)$ & 5 & $11.3-15.7$ & 11.8 & $12.7-19.5$ \\
\hline$\gamma$-glob $(\mathrm{g} / \mathrm{L})$ & 5 & $5-6.1$ & 5.5 & $9.1-17.5$ \\
\hline PCV $(\%)$ & 6 & $36-47$ & 45 & $24-42$ \\
\hline
\end{tabular}

CK, creatine kinase; LDH, lactate dehydrogenase; AST, aspartate aminotransferase; BUN, blood urea nitrogen; Vit. E, vitamin E; Se, selenium; TP, serum total proteins; $\alpha$-glob, $\alpha$-globulins; $\beta$-glob, $\beta$-globulins; $\gamma$-glob, $\gamma$-globulins; NP, not performed.

indicated frequent ventricular premature beats in all cases.

\section{Echocardiography}

Echocardiographic examinations were performed on 2 calves 4 days after doxycycline treatment had been discontinued. Results (Table 2) show that LVID was increased in calf 2 in systole $(4.7 \mathrm{~cm})$ as well as in diastole $(5.9 \mathrm{~cm})$. On the contrary, size of the left ventricle in calf 1 ( $3.3 \mathrm{~cm}$ in systole and $4.7 \mathrm{~cm}$ in diastole) was within normal limits. In the 2 investigated calves, FS ( 29.8 and $20.3 \%)$, FVI $(14.6$ and $10.9 \mathrm{~cm})$, ET $(250$ and $235 \mathrm{~m} / \mathrm{s})$, TTP $(109$ and $72 \mathrm{~m} / \mathrm{s}), \mathrm{SV}(41.3$ and $27.7 \mathrm{~mL} /$ beat $)$, CO $(5.2$ and $3.4 \mathrm{~L} / \mathrm{min})$, and SI $(0.60$ and $0.43 \mathrm{~mL} / \mathrm{beat} / \mathrm{kg})$ tended to be lower and PEP ( 44 and $58 \mathrm{~m} / \mathrm{s}$ ) and PEP/ET $(0.18$ and 0.25$)$ tended to be higher as compared with values previously reported in healthy $\mathrm{BB}$ calves. ${ }^{6,7} \mathrm{PFV}$ $(0.68 \mathrm{~m} / \mathrm{s})$ and $\mathrm{CI}(52.3 \mathrm{~mL} / \mathrm{min} / \mathrm{kg})$ tended to be lower in calf 2 than values previously reported in healthy BB calves. ${ }^{7}$

\section{Medications}

During their hospitalization, affected calves received different treatments: atropine $(\mathrm{n}=10)$, vitamin $\mathrm{E} /$ selenium $(n=7)$, oxytetracycline $(n=5)$, ceftiofur $(n=5)$, tilmicosin $(n=5)$, flunixin meglumine $(n=5)$, and florfenicol $(n=1)$ and combinations of these drugs.

\section{Postmortem Findings}

Postmortem examinations were performed on 22 calves ( 8 calves that died during hospitalization and 14 calves referred dead). Postmortem finding are presented in Table 3. Gross necropsy findings were similar regardless of the farm of origin. Histopathology indicated that the extent and severity of the muscular degenerative process varied among calves and muscles evaluated. The most severe lesions were observed in the tongue. Affected muscle fibers, interspersed among normal fibers, were hypereosinophilic, devoid of cross-striations and myofibrils, and displayed a homogenous hyaline glassy appearance. Numerous abnormal fibers exhibited a flocculent or granular pattern. The cytoplasm frequently was

Table 3. Postmortem findings in 22 calves with a suspicion of doxycycline intoxication necropsied at the veterinary medicine faculty of Liege.

\begin{tabular}{|c|c|c|}
\hline Organ or System & Gross Pathology & Histopathology \\
\hline Tongue & Tongue discoloration $(\mathrm{n}=10)$ & $\begin{array}{l}\text { Number of examined calves }=10 \\
\text { Myopathy (multifocal and polyphasic degeneration/necrosis) and } \\
\text { subacute to chronic glossitis (extensive mononuclear cells } \\
\text { infiltration) }(\mathrm{n}=10)(\text { Fig } 3)\end{array}$ \\
\hline Myocardium & $\begin{array}{l}\text { Extensively interspersed with white spots and } \\
\text { strands }(\mathrm{n}=22)(\text { Fig } 1)\end{array}$ & $\begin{array}{l}\text { Number of examined calves }=22 \\
\text { Extensive acute multifocal and polyphasic degeneration/necrosis, myolisis } \\
\text { with subacute cellular infiltration of macrophages }(n=22)(\text { Fig } 4)\end{array}$ \\
\hline Striated muscles & $\begin{array}{l}\text { Discoloration of some striated muscles } \\
\text { (diaphragm, mm intercostals externi, } \\
\text { m.biceps brachii, m.semitendinosus, } \\
\text { m.semimembranosus) }(\mathrm{n}=9) \text { (Fig 2) }\end{array}$ & $\begin{array}{l}\text { Number of examined calves }=9 \\
\text { Monophasic and multifocal degeneration/necrosis and subacute limited } \\
\text { myositis with macrophage infiltration (diaphragm, mm intercostals } \\
\text { externi, m.biceps brachii, m.semitendinosus, m.semimembranosus) } \\
\text { (Figs } 5 \text { and 6) }\end{array}$ \\
\hline Lungs & $\begin{array}{l}\text { Variable degrees of interstitial pneumonia } \\
\text { and/or pulmonary edema but this edema } \\
\text { was severe in only } 2 \text { calves }(\mathrm{n}=22)\end{array}$ & $\begin{array}{l}\text { Number of examined calves }=9 \\
\text { Variable degrees of subacute interstitial or alveolar pneumonia }\end{array}$ \\
\hline Urinary system & $\begin{array}{l}\text { Brown-colored urine }(\mathrm{n}=3) \\
\quad \text { Patchy congestion of the kidneys }(\mathrm{n}=1)\end{array}$ & $\begin{array}{l}\text { Number of examined calves }=12 \\
\text { Multifocal acute tubular necrosis }(\text { ATN }) \text { with neutrophils infiltration } \\
\quad(\mathrm{n}=7) \\
\text { Acute to subacute interstitial nephritis with mononuclear cells } \\
\quad \text { infiltration }(\mathrm{n}=2) \\
\text { Presence of hyaline or granular red-brown casts }(\mathrm{n}=10)\end{array}$ \\
\hline Liver & Liver congestion or fatty degeneration $(n=4)$ & $\begin{array}{l}\text { Number of examined calves }=1 \\
\quad \text { Mild diffuse acute hepatitis }(\mathrm{n}=1)\end{array}$ \\
\hline
\end{tabular}




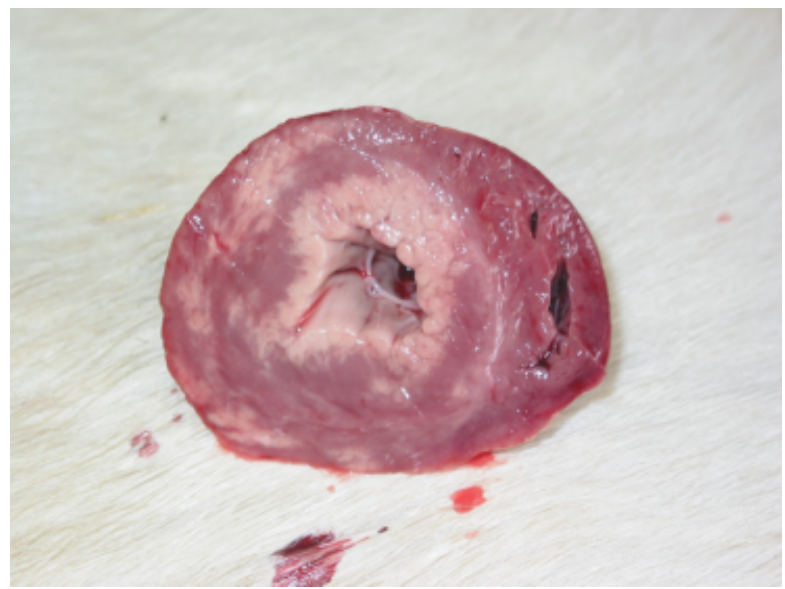

Fig 1. Myocardial discoloration.

fragmented into blocks scattered along the sarcolemnal tubes of persisting external lamina of muscle fibers. In some cases, sarcolemnal tubes were invaded with macrophages. Foci of fibroblastic proliferation also were observed. Lesions observed in the myocardium were similar to those observed in the tongue but appeared to be more acute. Lesions observed in the sampled striated muscles were similar but less severe than those observed in the myocardium.

\section{Discussion}

In this retrospective study, oral intake of high doses of doxycycline by calves mainly resulted in clinical, biochemical, ECG, echocardiographic, necropsy and histopathological alterations consistent with acute necrotic myopathy and cardiomyopathy, interstitial nephritis, and acute renal tubular necrosis. Muscular and myocardial lesions corroborate previous descriptions made on doxycycline-overdosed calves. However, to the authors' knowledge, this is the 1st report of renal lesions in doxycycline-overdosed calves.

Affected calves of this study were 4 to 16 weeks old, were of different breeds and from different farms and

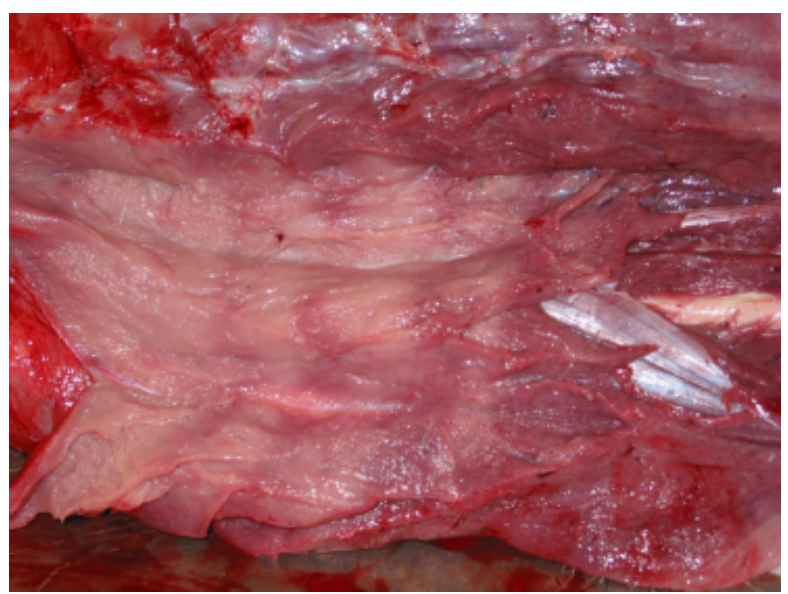

Fig 2. Striated muscles discoloration.

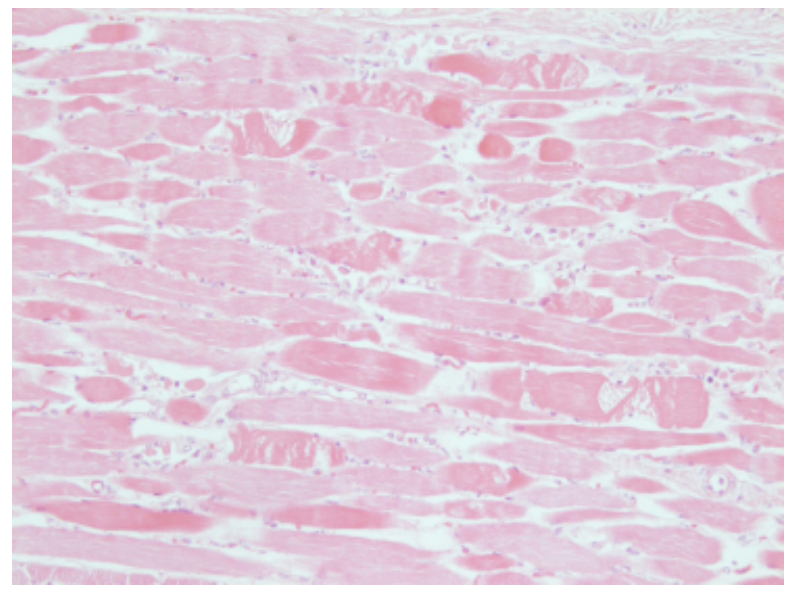

Fig 3. Tongue $\times 200$, hematoxylin and eosin.

showed clinical signs 2 to 4 days after the onset of doxycycline treatment. These observations corroborate previous studies performed in doxycycline-poisoned calves $^{6,8,9}$ (McEwen, personal communication) and suggest that there is no breed or genetic predisposition for doxycycline toxicity in calves.

Sialorrhea, tongue dysfunction, and dysphagia were clinical signs observed in the doxycycline-overdosed calves of the present study as well as in those of previous studies. ${ }^{3,4}$ Histopathologic lesions in the tongue in the present study were severe enough to cause substantial dysfunction of the tongue, similar to those described by Chiers and colleagues, and could explain the observed dysphagia. Dysphagia also has been attributed in previous studies to pharyngeal paralysis resulting from degenerative lesions of pharyngeal muscles observed in doxycycline-poisoned calves, ${ }^{4}$ which was not investigated in the present study.

When present, tongue dysfunction and sialorrhea were reported to be the earliest clinical signs in the affected calves of the present as well as previous studies. ${ }^{4}$ On the other hand, histopathology results of the present study indicated that the pathologic process in the tongue was less acute than that in the myocardium, suggesting that

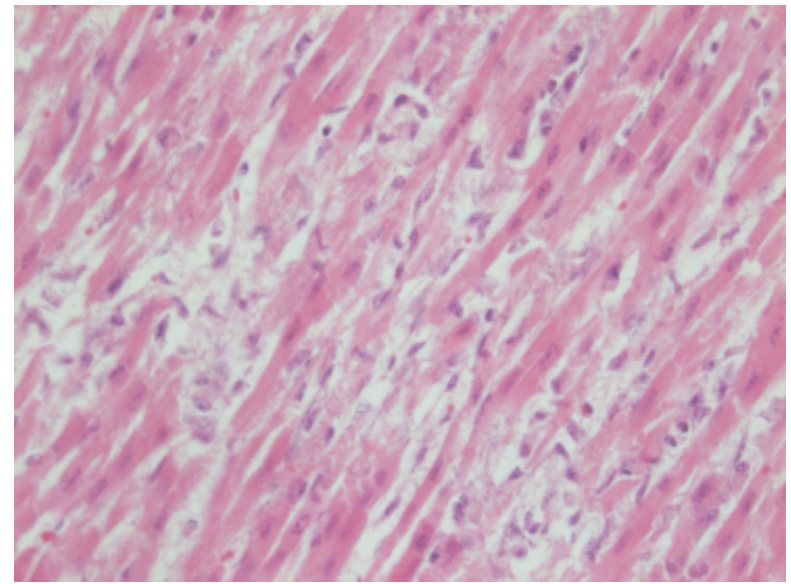

Fig 4. Myocardium $\times 400$, hematoxylin and eosin. 


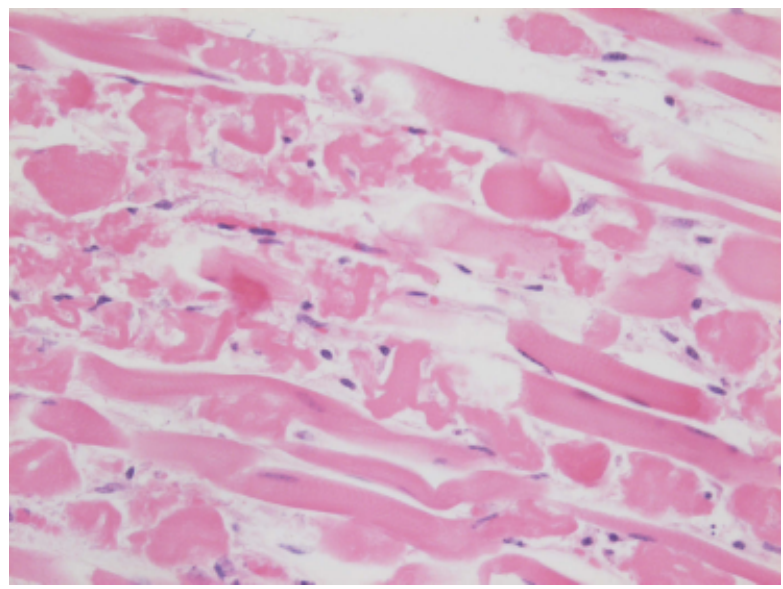

Fig 5. Diaphragm $\times 400$, hematoxylin and eosin.

the tongue muscle was affected before the myocardium. Taken together, these results suggest an early effect of doxycycline on the tongue in overdosed calves.

Tachypnea and dyspnea also are clinical signs that have been reported in doxycycline-poisoned calves of the present as well as previous studies. ${ }^{3,4}$ Even if these signs were present before doxycycline treatment, their exacerbation could be associated with the necrosis of the respiratory muscles observed by histopathology. Dyspnea also could partly be explained by the pulmonary edema observed either in this study or in previous reports of doxycycline-poisoned calves. ${ }^{1,3}$ It is difficult to distinguish if this edema was because of respiratory disorders present before doxycycline treatment or if it was a consequence of doxycycline overdosing.

In the present study, blood analysis (4 calves) and histopathology (12 calves) indicated renal lesions or impairment. The observed azotemia was probably because of an acute tubular necrosis (ATN) as observed on histopathology. ATN is the most common cause of acute renal failure ${ }^{8}$ and results from 2 mechanisms: ischemia or toxic damage to the renal tubular cells. ${ }^{6,7}$ Other but less frequent causes of renal tubular damage are blood-borne infections and ascending infections. ${ }^{9}$

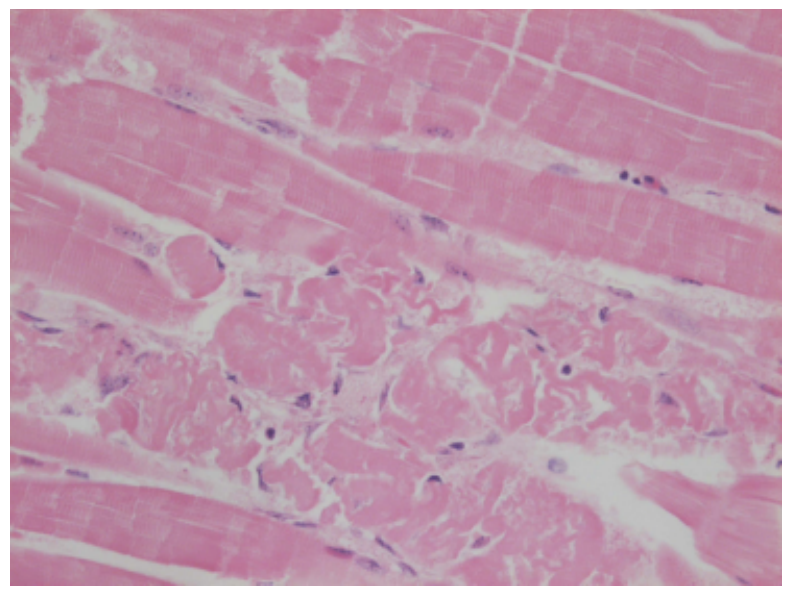

Fig 6. M.semimembranosus $\times 400, H \& E$.
The renal tubules are particularly susceptible to a wide variety of toxic agents as a consequence of their high metabolic activity, exposure to agents in the large volume of ultrafiltrate, ${ }^{8}$ and the concentration of the toxin or its metabolites within the renal tubular lumina. ${ }^{9}$ Additionally, many of these metabolites can indirectly stimulate vasoconstriction and ischemia, which further compromises renal function. ${ }^{9}$

Tetracyclines are known to induce dose-related functional changes in renal tubules in several species. ${ }^{10,11}$ In ruminants, prolonged administration and high doses of tetracyclines were associated with renal failure secondary to renal tubular necrosis, ${ }^{9-12}$ which seems to be exacerbated by dehydration and myoglobinuria. ${ }^{11}$ However, doxycycline has been reported to produce fewer adverse renal effects than other tetracyclines, ${ }^{8,13-15}$ and the only description of doxycycline-induced nephrotoxicity was made in a human patient after 12 years of doxycycline self-medication. ${ }^{16}$ The low renal toxicity of doxycycline may be a result of its excretion primarily by the fecal route, ${ }^{14,15}$ whereas the other tetracyclines, except minocycline, are excreted unchanged by the kidney and, to a lesser extent, by the liver. ${ }^{14,17}$ Glomerular filtration does not appear to be of importance for doxycycline excretion. ${ }^{18}$ Moreover, when used at recommended doses, doxycycline concentrations do not tend to accumulate substantially in the blood of human patients with renal failure. ${ }^{14,15,19}$ Doxycycline thus has been reported to be one of the safest tetracyclines for use in patients with renal impairment. ${ }^{14,19,20}$

On the other hand, notably decreased renal perfusion from any cause can result in renal tubular necrosis that may be complicated by myoglobinuria. ${ }^{9}$ In small animals ${ }^{9}$ and in ruminants, ${ }^{21}$ decreased CO is reported to be a cause of acute renal ischemia, probably because 20 $25 \%$ of CO normally flows to the kidneys. ${ }^{9}$ Myoglobin is not primarily nephrotoxic in itself, ${ }^{8,9}$ but its presence in the glomerular filtrate can increase the tubular necrosis that occurs as a result of renal ischemia. ${ }^{8,9}$

These findings suggest that ATN and the subsequent renal impairment observed in the calves of this study may be the result of a combination of ischemic events secondary to a cardiomyopathy-induced decrease in $\mathrm{CO}$, and an exacerbating role of myoglobin released from damaged muscular tissue.

In this study, the increase in SDH activity in 6 calves and the postmortem hepatic lesions in 4 other calves indicate hepatic damage in doxycycline-poisoned calves. Increases in SDH activity indicate active and ongoing hepatocellular damage. ${ }^{22-24}$ With respect to the age of the animals in this study, hepatic lipidosis observed in two of the necropsied calves is probably the result of toxic or anoxic causes or both. $^{25,26}$ These can induce sublethal reversible injury to hepatocytes that results in decreased formation or export of lipoproteins by hepatocytes or both and decreased oxidation of fatty acids in hepatocytes. The final result is accumulation of lipids within affected cells. ${ }^{25,26}$ Other causes of hepatic lipidosis can be eliminated because of age or species characteristics.

Tetracycline-induced liver damage has been described in humans ${ }^{15}$ and animals with ${ }^{17}$ or without ${ }^{10}$ pre-existing 
renal failure. In cattle, high doses of oxytetracycline have led to fatty infiltration of the liver. ${ }^{10}$ Although doxycycline is potentially less hepatotoxic than tetracycline, ${ }^{27}$ some reports have linked it with liver injury in humans ${ }^{28}$ where fatty degeneration, hepatocellular necrosis, and cholestasis were reported as unusual manifestations after chronic treatment with doxycycline. ${ }^{16}$

Lack of appetite was observed in the calves of this study and in previous reports. ${ }^{3}$ Bad taste of the doxycycline-milk mixture is not likely to be an explanation because the calves ingested the mixture spontaneously. The lack of appetite may be a result of tongue myopathy, general clinical deterioration, renal impairment, or a combination of these factors.

In the calves of this study, sudden death may have been caused by the stress of handling, examination, or feeding. A similar phenomenon was described in cattle with monensin-associated cardiomyopathy ${ }^{29}$ and in calves suffering from cardiomyopathy induced by vitamin $\mathrm{E}$ and selenium deficiency. ${ }^{30-32}$

The myocardial necrosis observed in the calves of this study was likely responsible for death because no other concomitant lesion, especially pulmonary lesions, was severe enough to explain the death of these animals.

Echocardiographic examination results of this study must be considered with caution because this investigation was performed on only 2 affected calves and 4 days after doxycycline treatment had been discontinued. However, the results obtained in calf 2 suggest severe impairment of global cardiac performance associated with a decrease in systolic function (low SV, CO, FS, PFV, FVI, ET and high PEP, and PEP/ET ratio). Low values of FS, ET, SV, and CO may be secondary to a poor cardiac preload, increased afterload, or decreased myocardial contractility, whereas high values of PEP and PEP/ET can be associated with a decrease in cardiac preload or impaired myocardial contractility. ${ }^{5}$

In calf 2 , a decrease in cardiac preload can be eliminated because LVIDd was increased as compared with reference values. Cardiac afterload was not evaluated in this calf because this parameter is difficult to assess in vivo. Impaired systolic function in this calf likely was the result of a decreased myocardial contractility, as suggested by the decreased FS and increased PEP/ET, even if an increase in afterload could also be possible. This disturbance of myocardial contractility could be explained by the myocardial necrosis observed in all of the necropsied calves.

Other known cardiomyopathies in cattle are hereditary cardiomyopathies, toxic cardiomyopathies (caused by monensin, maduramicin, lasalocid, and salinomycin) and nutritional cardiomyopathies (vitamin $\mathrm{E}$ and selenium deficiency).

Although doxycycline is a commonly used drug in human medicine, necrotic cardiomyopathy has never been described as an adverse effect of doxycycline in humans. This difference could be explained by a more careful dosing in humans or by species variability in the toxicity of this drug.

Adverse cardiac effects of doxycycline in species other than cattle seem to be very rare. In humans, arrhythmias were described as complications of intrapericardial doxycycline sclerosis in the treatment of malignant pericardial effusion $^{33}$ and in a unique case of 12 years of selfmedication with doxycycline. ${ }^{16}$ Supraventricular tachycardia followed by sudden death also has been reported in horses after IV infusion of doxycycline, ${ }^{34}$ but not after PO administration. ${ }^{35}$ Some authors suggested that these untoward effects in horses may be the result of chelation of calcium ions in the cytosol or on the surface of myocardial cells and smooth muscles cells of blood vessels. ${ }^{34}$ Yeruham et al suggested that a similar pathophysiologic mechanism also may occur in ruminants. ${ }^{3}$ This seems paradoxical with the fact that calcium is not chelated by doxycycline as reported by some authors. ${ }^{15,36}$ Doxycycline seems to be less susceptible to this interaction and it can be administered to children even when mixed with milk, and remain stable for 6 days when refrigerated. ${ }^{15}$ Some other factors thus could contribute to development of cardiomyopathy in doxycycline-overdosed calves. Because the exact mechanism still is unclear, doxycycline therapy in calves should be managed cautiously by careful calculation of BW and dosage.

\section{Conclusion}

As reported in previous studies, this retrospective study shows that overdosing doxycycline in calves resulted in adverse effects consistent with necrotic myopathy and cardiomyopathy. In addition to these muscular and cardiac complications, overdosing doxycycline in calves resulted in renal damage.

\section{Footnotes}

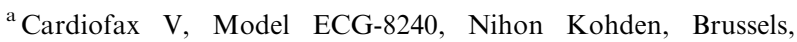
Belgium

${ }^{\mathrm{b}}$ GE Medical Systems, RT6800, London, UK
}

\section{References}

1. Zeeuwen AAPA, Van Exsel ACA, Jaartsveld FHJ, et al. Doxycycline-vergiftiging bij witvleeskalveren. Tijdschr Diergeneeskd 1993;118:803.

2. Mcewen B, Lusis P, Archambault M, et al. Doxycycline cardiotoxicity in veal calves. AHL Newsletter 2002;6:5.

3. Yeruham I, Perl S, Sharony D, et al. Doxycycline toxicity in calves in two feedlots. J Vet Med 2002;49:406-408.

4. Chiers K, Weyens P, Deprez P, et al. Lingual and pharyngeal paralysis due to acute doxycycline intoxication in veal calves. Vet Rec 2004; 155:25-26.

5. Boon JA. Manual of Veterinary Echocardiography. Baltimore, MD: Williams and Wilkins; 1998:35-236.

6. Amory H, Kafidi N, Lekeux P. Echocardiographic evaluation of cardiac morphologic and functional variables in double-muscled calves. Am J Vet Res 1992;53:1540-1547.

7. Brihoum M, Rollin F, Desmecht D, et al. Evaluation of systolic function in calves by Doppler echocardiography: Preliminary results. In: 24th World Buiatrics Congress Proceedings, Nice, France, 2006. 
8. Maxie GM, Newman SJ. Urinary system. In: Maxie MG, ed. Jubb, Kennedy, and Palmer's Pathology of Domestic Animals, 5th ed. Edinburgh: Saunders Elsevier; 2007:425-522.

9. Newman SJ, Confer AW, Panceira RJ. Urinary system. In: Mcgavin MD, ed. Pathologic Basis of Veterinary Disease, 4th ed. St Louis, MO: Mosby Elsevier; 2007:613-619.

10. Griffin DD, Morter RL, Amstutz HE, et al. Experimental oxytetracycline toxicity in feedlot heifers. Bovine Pract 1979; $14: 37-41$

11. Riond JL, Riviere JE. Effects of tetracyclines on the kidney in cattle and dogs. J Am Vet Med Assoc 1989;195:995-997.

12. Confer AW, Panceira RJ. The urinary system. In: Mcgavin MD, Carlton WW, Zachary JF, eds. Thomson's Special Veterinary Pathology, 3rd ed. St Louis, MO: Mosby; 2001:235-237.

13. Ahrens FA, Martin RJ. Antimicrobial drugs. In: Hsu WH, ed. Handbook of Veterinary Pharmacology. Ames, IA: WileyBlackwell; 2008:347-378.

14. Chambers HF. Protein synthesis inhibitors and miscellaneous antibacterial agents. In: Brunton LL, Lazo JS, Parker KL, eds. Goodman and Gilman's The Pharmacological Basis of Therapeutics, 11th ed. New York: McGraw-Hill; 2006:1173-1179.

15. Papich MG, Riviere JE. Tetracycline antibiotics. In: Riviere JE, Papich MG, Adams HR, eds. Veterinary Pharmacology and Therapeutics, 9th ed. Ames, IA: Wiley-Blackwell; 2009:895-913.

16. Westermann GW, Bohm M, Bonsmann G, et al. Chronic intoxication by doxycycline use for more than 12 years. J Intern Med 1999;246:591-592.

17. Giguère $S$. Tetracyclines and glycylcyclines. In: Giguère $S$, Prescott JF, Baggot JD, Walker RD, Dowling PM, eds. Antimicrobial Therapy in Veterinary Medicine, 4th ed. Ames, IA: Blackwell Publishing; 2006:231-240.

18. Wilson RC, Kemp DT, Kitzman JV, et al. Pharmacokinetics of doxycycline in dogs. Can J Vet Res 1988;52:12-14.

19. Plumb DC. Doxycycline. In: Plumb DC, ed. Plumb's Veterinary Drug Handbook. Ames, IA: Blackwell Publishing; 2008;331.

20. Shaw DH, Rubin SI. Pharmacologic activity of doxycycline. J Am Vet Med Assoc 1986;189:808-810.

21. Radostits OM. Veterinary Medicine: A Textbook of the Diseases of Cattle, Horses, Sheep, Pigs and Goats. Edinburgh: Saunders Elsevier; 2007:543-574.

22. Tennant BC. Hepatic function. In: Kaneko JJ, Harvey JW, Bruss ML, eds. Clinical Biochemistry of Domestic Animals, 5th ed. London: Academic Press; 1997:327-352.
23. Lassen ED. Laboratory evaluation of the liver. In: Thrall MA, Baker DC, Campbell TW, eds. Veterinary Hematology and Clinical Chemistry. Baltimore, MD: Lippincott Williams \& Wilkins; 2004:355-375.

24. Carlson GP. Clinical chemistry tests. In: Smith BP, ed. Large Animal Internal Medicine, 4th ed. St Louis, MO: Mosby; 2009: 375-397.

25. Cullen JM. Liver, biliary system, and exocrine pancreas. In: Mcgavin MD, ed. Pathologic Basis of Veterinary Disease, 4th ed. St Louis, MO: Mosby Elsevier; 2007:393-461.

26. Myers RK, Mcgavin MD. Cellular and tissue responses to injury. In: Mcgavin MD, ed. Pathologic Basis of Veterinary Disease, 4th ed. St Louis, MO: Mosby Elsevier; 2007:3-62.

27. Heaton PC, Fenwick SR, Brewer DE. Association between tetracycline or doxycycline and hepatotoxicity: A population based case-control study. J Clin Pharm Ther 2007;32:483-487.

28. Bjornsson E, Lindberg J, Olsson R. Liver reactions to oral low-dose tetracyclines. Scand J Gastroenterol 1997;32:390-395.

29. Sauvageau R, Cecyre A, Phaneuf JB, et al. Intoxication au monensin chez des bovins à l'engraissement. Med Vet Quebec 1984;14:170-173.

30. Cawley GD, Bradley R. Sudden death in calves associated with acute myocardial degeneration and selenium deficiency. Vet Rec 1978;103:239-240.

31. Rogers PAM, Poole DBR. Sudden death in calves. Vet Rec 1978;103:366.

32. Mee JF, Rogers PAM. Sudden death in bucket-reared calves. Irish Vet J 1990;43:61-66.

33. Maher EA, Shepherd FA, Todd TJ. Pericardial sclerosis as the primary management of malignant pericardial effusion and cardiac tamponade. J Thorac Cardiovasc Surg 1996;112:637-643.

34. Riond JL, Riviere JE, Duckett WM, et al. Cardiovascular effects and fatalities associated with intravenous administration of doxycycline to horses and ponies. Equine Vet J 1992;24:41-45.

35. Davis JL, Salmon JH, Papich MG. Pharmacokinetics and tissue distribution of doxycycline after oral administration of single and multiple doses in horses. Am J Vet Res 2006;67: $310-316$.

36. Van Gool F, Santoul C, Raynaud JP. Caracteristiques pharmacocinetiques et bilan des essais cliniques pour le traitement ou la metaphylaxie des bronchopneumonies infectieuses des veux de boucherie par le Ronaxan $\AA$. Proceedings of the 14th World Congress on Diseases of Cattle, Dublin 1986; 1:627-631. 